JHR

32,4

\section{2}

Received 18 April 2017 Accepted 2 May 2018

\title{
Universal Health Coverage (UHC)
}

\author{
Samlee Plianbangchang \\ College of Public Health Sciences, Chulalongkorn University, Bangkok, Thailand
}

\begin{abstract}
Purpose - The WHO Health for All goal of the year 2000 was unreachable due to a number of irreconcilable factors. However, governments agree that a resolution must be found to effectively cope with increasing health care costs. Furthermore, national health insurance schemes must be properly refined to suit local situations. Workable health policies and strategies for caring and treating sick people through reduced or cost effective methods must be developed as part of a Universal Health Coverage scheme. A review of progress made toward achieving the WHO goal of health for all. The purpose of this paper is to explore the government's role and responsibilities to educate and support society to achieve optimum health.

Design/methodology/approach - This is a commentary piece.

Findings - Participation and involvement of all people of all walks of life in the development and management of their nation's health care programs is an important requisite of good health for all. This should include financial participation and co-payment into the national health insurance scheme. Furthermore, national health care systems should involve or include the traditional/local and alternative systems of medicine in the most appropriate manner. Health care has to encompass the total range of comprehensive health interventions, inclusive of at least preventive, curative and rehabilitative care.

Originality/value - This paper provides a review of the current health system constraints and assesses the effectiveness of available options by way of ensuring that a country-specific UHC system may be successfully implemented.
\end{abstract}

Keywords Health, Universal Health Coverage

Paper type Commentary

\section{Health for All by the Year 2000 (HFA/2000)}

At the World Health Assembly in 1977, all member states of the World Health Organization (WHO), resolved to set a goal of "Health for All by the Year 2000" for governments and the WHO to collaboratively work toward achieving healthy living standards, thereby ensuring a socially and economically productive life[1].

A year later in 1978, at the international conference on Primary Health Care (PHC) at Alma Ata, USSR, it was declared that a PHC) approach was the key to health for all by the year 2000[2]. This approach focused on health care being made universally accessible to individuals and families, with their full participation and involvement, and at a cost that the community and country could afford because it benefits the community's overall social and economic development.

Based on PHC principles, almost every country developed their respective national strategies for health for all by the year 2000 , which was then consolidated into the Global Strategy for Health For All by the year 2000.

The Global Strategy[3] was then implemented coordinately and cooperatively, and more world resources were mobilized to support its implementation. However, it became evident to the WHO that not everyone could equally benefit from the implementation of this global strategy. It was observed that, in general, there were signs of health improvement evidenced by healthier people living for longer, especially in developing countries.

In spite of the fact that the 1977 target for the year 2000 was not completely achieved, the WHO decided to maintain the "Health For All" goal as an aspirational target. Rather than a

(c) Samlee Plianbangchang. Published in the Journal of Health Research. Published by Emerald Publishing Limited. This article is published under the Creative Commons Attribution (CC BY 4.0) licence. Anyone may reproduce, distribute, translate and create derivative works of this article (for both commercial and non-commercial purposes), subject to full attribution to the original publication and authors. The full terms of this licence may be seen at http://creativecommons.org/licences/by/4.0/legalcode 
fixed target date, this aspirational goal was established to inspire, motivate and encourage all countries to do more for the health improvement of their people and invest in the improvement of health systems and infrastructures for the sustainable development of global health.

Universal Health Coverage (UHC)

\section{Post Health for all by the Year 2000 (HFA/2000)}

There are many reasons why the goal of HFA/2000 could not be attained. The reasons were broadly determined in the areas of social, economic and environmental domains outside the capacity of individual countries to control, particularly in the case of developing countries. However, due to a global and regional spirit of unity and solidarity, as well as strong advocacy and the coordinated action of the WHO, efforts were made toward achieving health for all. A PHC approach was developed and the idea of a Universal Health Coverage (UHC) system[4] was considered to be an important requisite of the "Health for All" goal.

Many countries worldwide have been keenly interested in the application of the UHC idea, seeing it as a driving force to support governments toward achieving the goal of good health for all their people. Due to the increasing numbers of sick in need of effective medical treatment and care, increased investment is required to meet the demand for improved medical infrastructure and the improvement of high-quality medical care and services. The cost of medical treatment and necessary requirement to support and care for the sick is fast becoming a great financial burden to governments worldwide. In an attempt to finance health care services, several health insurance schemes have been conceptualized, and also, several national systems of health insurance have been developed. However, there is not a universally applicable system for any specific country to cope with the steady increase in health care costs. The number of sick, ill or disabled people increases unabatedly. The situation is further compounded by the emergence of chronic non-communicable diseases which need long-term treatment and care that is expensive, coupled with the great risk of emerging infectious diseases due to environment degradation, as well as injuries and death due to road traffic accidents and occupational hazards, all of which are intractable to prevention and control measures.

The main points for consideration and discussion in relation to a cost-efficient plan for developing a health improvement plan are as follows:

- It is not possible to develop a single model regarding a health insurance scheme or system to fit all situations as each model depends on the social and economic context, as well as political and governance system, population size, and demographic and epidemiologic profiles of the countries concerned.

- In health development, there should be more investment in health promotion and disease prevention that emphasizes prevention and control of sickness, illness and disability through community-based multi-sectorial and multidisciplinary collaboration and actions against the prevailing health risks.

- Promotion of self- reliance and community resilience in health should be encouraged through the support and facilitation of "Self-care" activities at individual, family and community levels[5].

- Ambulatory care or community health care should be vigorously promoted and supported through the application of a PHC approach as an integral part of national health care and national health insurance systems.

- Community health workforce, including the scheme of community health volunteers, must be strengthened in both quantitative and qualitative terms to ensure effective implementation of a PHC approach at community and grassroots levels.

- Effective functioning of the two-way referral systems from primary care to secondary care and tertiary care must be ensured at all time; this referral system is 
to guarantee linkage and continuity of health care between family, community, institutions and workplaces.

- It is necessary to keep in mind that the availability of care and services is not exactly the same as the accessibility to care and services; the care and services may be available, but with many reasons they may not be accessible by all people who are in need.

- It may be easier to develop a system of health insurance to cover all citizens in the country of small population size and of small geographical area. But it will be harder in the bigger countries.

- The countries with more resources, a wealthier population and more effective taxation systems have a better chance to be successful in the development of health insurance schemes to serve their entire populations.

- National health insurance systems should be opened to the participation and involvement of private and voluntary organizations with effective regulatory control by the governments. It may be desirable if the national health insurance system is of a mixed type, comprising of both public and private health insurance schemes.

\section{Conclusions}

Good health for all people may be effectively achieved through the balanced development of both medical and public health care (curative and preventive) provided in all settings: institutions, communities and workplaces.

Through an effective, comprehensive and integrated health care system, balancing between the development of medical and public health (treatment and prevention) care, nations will be able to achieve the goal of a "healthy population" in real terms, which is indeed needed for successful social and economic development toward national wealth and prosperity.

\section{References}

1. World Health Organization [WHO]. World Health Assembly Resolution WHA 30.43, Health for All by the Year 2000. Geneva: WHO; 1977 (WHO Health for All Series No. 2).

2. World Health Organization [WHO]. Primary Health Care: Alma Ata Declaration 1975. Geneva: WHO; 1978 (WHO Health for All Series, No. 1).

3. World Health Organization [WHO]. Global Strategy for Health for All by the Year 2000. Geneva: WHO; 1981 (WHO Health for All Series, No. 3).

4. World Health Organization [WHO]. Universal Health Coverage: 2017 [cited 2017 Apr]. Available from: www.who.int/universal_health_coverage/en/

5. Wikipedia. Self-care: 2017 [cited 2017 Apr]. Available from: https://en.wikipedia.org/wiki/Self_-_care

\section{Corresponding author}

Samlee Plianbangchang can be contacted at: samleep40@gmail.com

For instructions on how to order reprints of this article, please visit our website: 